\title{
Fibrillation in patients subjected to coronary artery bypass grafting
}

\author{
Zhong-Kai $\mathrm{Wu}, \mathrm{MD}, \mathrm{PhD}^{\mathrm{a}}$ \\ Tiina livainen, $\mathrm{MD}, \mathrm{PhD}^{\mathrm{b}}$ \\ Erkki Pehkonen, MD, PhD \\ Jari Laurikka, MD, $\mathrm{PhD}^{\mathrm{a}}$ \\ Sijian Zhang, MD, $\mathrm{MSc}^{\mathrm{C}}$ \\ Matti R. Tarkka, MD, PhD
}

From the Division of Cardiothoracic Surgery, ${ }^{a}$ Department of Surgery, and the Department of Clinical Physiology, ${ }^{\mathrm{b}}$ Tampere University Hospital, Tampere, Finland, and the Biostatistics and Bioinformatics Unit, ${ }^{\mathrm{c}}$ Comprehensive Cancer Center, University of Alabama at Birmingham, Birmingham, Ala.

Supported by the Research Foundation of Tampere University Hospital.

Received for publication Aug 1, 2002; revisions requested Sept 6, 2002; revisions accepted Oct 28, 2002; accepted for publication Jan 23, 2003.

Address for reprints: Matti R. Tarkka, MD, Division of Cardiothoracic Surgery, Department of Surgery, Tampere University Hospital, 33521, Tampere, Finland (E-mail: matti.tarkka@tays.fi).

J Thorac Cardiovasc Surg 2003;126: 1477-82

Copyright ( $(2003$ by The American Association for Thoracic Surgery

$0022-5223 / 2003 \$ 30.00+0$

doi:10.1016/S0022-5223(03)00749-9
Objective: Atrial fibrillation is the most frequently encountered postoperative arrhythmic complication after coronary artery bypass grafting. Ischemic preconditioning has proved a potent endogenous factor in suppressing ischemia-reperfusioninduced arrhythmias. The protective effect of ischemic preconditioning on atrial fibrillation after coronary artery bypass grafting has not been studied. The purpose of the present study was to investigate whether ischemic preconditioning had an effect on postoperative atrial fibrillation in patients undergoing coronary artery bypass grafting.

Methods: Eighty-five patients undergoing coronary artery bypass grafting were randomized into ischemic preconditioning and control groups. Holter data from 24-hour electrocardiography were collected 1 day before the operation to the second postoperative day. Atrial fibrillation was registered as positive if any atrial fibrillation event occurred.

Results: The overall incidence of postoperative atrial fibrillation and sustained atrial fibrillation was $34.1 \%$ and $27.1 \%$, respectively. The occurrence of atrial fibrillation was significantly lower in the ischemic preconditioning group (21.4\% in patients undergoing ischemic preconditioning and $46.5 \%$ in control subjects, $P=.015$ ). Preoperative recent unstable angina did not influence the incidence of atrial fibrillation. Patients with atrial fibrillation had longer intensive care unit stays and compromised postoperative hemodynamic outcomes. Binary logistic regression analysis showed that ischemic preconditioning, preoperative mean heart rate, and postoperative pulmonary capillary wedge pressure were the independent predictors of atrial fibrillation.

Conclusions: Postcoronary artery bypass grafting atrial fibrillation is associated with more complicated postoperative outcome. Higher preoperative heart rate and postoperative pulmonary capillary wedge pressure were the independent predictors of atrial fibrillation. Recent unstable angina is not related to the occurrence of postcoronary artery bypass grafting atrial fibrillation. Ischemic preconditioning significantly suppresses postcoronary artery bypass grafting atrial fibrillation, suggesting that ischemic preconditioning can be used as an effective prophylactic method for postoperative atrial fibrillation.

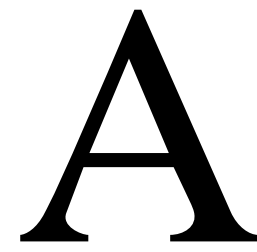

trial fibrillation (AF) is the most frequently encountered postoperative arrhythmic complication associated with coronary artery bypass grafting $(\mathrm{CABG}){ }^{1-9}$ Although rarely fatal, post-CABG AF might lead to subjective discomfort and anxiety, systemic embolization, iatrogenic complication, compromised hemodynamic function, hypotension, pulmonary edema, heart failure, longer hospitalization, and need for posthospital medication use. AF is also associated with 
TABLE 1. Perioperative data on IP and control group patients

\begin{tabular}{|c|c|c|c|}
\hline & $\begin{array}{c}\text { IP } \\
(n=42)\end{array}$ & $\begin{array}{l}\text { Control } \\
(n=43)\end{array}$ & $P$ value \\
\hline Preoperative transient AF & $2(4.8)$ & $2(4.7)$ & .981 \\
\hline Age (y) & $64.6 \pm 9.5$ & $65.9 \pm 9.2$ & .534 \\
\hline Sex (n female) & $10(23.8)$ & $11(25.6)$ & .850 \\
\hline Unstable & $20(47.6)$ & $21(48.8)$ & .911 \\
\hline $\begin{array}{l}\text { Left ventricular ejection } \\
\text { fraction }\end{array}$ & $60.3 \pm 11.2$ & $63.0 \pm 9.8$ & .247 \\
\hline NYHA classification & $3.5 \pm 0.7$ & $3.4 \pm 0.6$ & .805 \\
\hline Infarct history (>3 mo) & $21(50.0)$ & $18(41.9)$ & .451 \\
\hline Diabetics & $9(21.4)$ & $15(23.3)$ & .746 \\
\hline Risk factor (Cleveland model) & $1.7 \pm 1.8$ & $1.5 \pm 1.6$ & .551 \\
\hline $\begin{array}{l}\text { Preoperative use of } \beta \text { - } \\
\text { blocker }\end{array}$ & $38(90.5)$ & $39(90.7)$ & .972 \\
\hline $\begin{array}{l}\text { Preoperative use of } \\
\text { amiodarone }\end{array}$ & $1(2.4)$ & $1(2.3)$ & .987 \\
\hline $\begin{array}{l}\text { Preoperative use of ACE } \\
\text { inhibitor }\end{array}$ & $9(21.4)$ & $9(20.9)$ & .955 \\
\hline $\begin{array}{l}\text { Preoperative use of } \mathrm{Ca}^{++} \\
\text {antagonist }\end{array}$ & $13(31.0)$ & $12(27.9)$ & .758 \\
\hline Left main stenosis $>50 \%$ & $14(33.3)$ & $14(32.6)$ & .939 \\
\hline $\begin{array}{l}\text { Aortic crossclamping time } \\
\text { (min) }\end{array}$ & $80.6 \pm 17.8$ & $78.3 \pm 20.0$ & .570 \\
\hline Perfusion time (min) & $112.9 \pm 20.9$ & $108.3 \pm 19.0$ & .302 \\
\hline No. of bypasses & $3.8 \pm 0.8$ & $3.7 \pm 0.8$ & .292 \\
\hline
\end{tabular}

Preoperative transient AF was recorded during preoperative Holter monitoring. Continuous data are presented as means $\pm S D$, and categoric data were recorded as numbers of patients (\%). NYHA, New York Heart Association; $A C E$, angiotensin-converting enzyme.

increased 30-day and 6-month mortality and increased total cost of medical care. ${ }^{1-4,8,9}$ Many complications of coronary artery bypass surgery occur more often in patients who have postoperative AF than in patients who do not. ${ }^{1}$ Moreover, treatment of $\mathrm{AF}$ might fail or might be associated with potentially harmful side effects, such as the proarrhythmic effects of antiarrhythmic drugs, bleeding from anticoagulation, and recurrent hospital admission. ${ }^{2,3,8}$ Research for a suitable means of preventing post-CABG AF is thus clearly warranted.

Myocardial ischemic preconditioning (IP) has been extensively studied in various kinds of experimental models, as well as in human subjects. ${ }^{10-21}$ The approach has proved a potent endogenous factor in preserving high-energy phosphates, delaying myocardial infarction, and improving postischemic functional recovery. ${ }^{10-13}$ Myocardial preconditioning in experimental animals has been reported to be associated with decreased postischemic reperfusion arrhythmias, with these effects being apparently as potent as those induced with standard antiarrhythmic drugs. ${ }^{14-16}$ There is also evidence that IP suppresses both ventricular ${ }^{17-19}$ and atrial ${ }^{19-21}$ arrhythmias in the human heart. Whether IP protects the heart from postoperative AF in cardiac surgery has not been studied. The present purpose was to investigate whether IP had an effect on postoperative AF in patients with stable and unstable angina pectoris undergoing $\mathrm{CABG}$.

\section{Methods}

The study design was accepted by the Ethical Committee of Tampere University Hospital, Finland, and informed consent was obtained from all patients.

Eighty-nine consenting stable and unstable patients undergoing CABG were randomized into 2 groups: a control group and a study group receiving the IP protocol. All unstable patients had unstable angina pectoris within 3 days before the operation. This was diagnosed by means of electrocardiography (ECG) and treated with nitroglycerine infusion. Patients with recent myocardial infarction ( $<3$ months previous), the presence of preoperative basic rhythm of $\mathrm{AF}$, previous diagnosed paroxysmal AF, additional cardiac diseases (eg, valvular disease), severe noncardiac diseases (eg, pulmonary hypertension and renal failure), cardiac redo operations, and emergency operations were excluded from the study cohort.

Two patients in the control group and one in the IP group were excluded because of unnoticed accidental disconnection of the wires or malfunction of the Holter recording apparatus during 24-hour ECG. One IP group patient with preoperative basic rhythm of AF during the 24-hour ECG monitoring was also excluded from the study. This left a final study cohort of 85 patients (42 patients in the IP group and 43 patients in the control group). The preoperative characteristics of the patients in the respective groups were similar (Table 1).

\section{Preconditioning Protocol}

Cardiopulmonary bypass (CPB) was established, and the heart was vented. The aorta was then crossclamped for 2 minutes, followed by 3 minutes of reperfusion. The control group also had the pump running for 10 minutes before the routine operation.

\section{Anesthesia, CPB, and Surgical Technique}

A standardized anesthetic technique was used with sufentanil (7.8 $\mu \mathrm{g} / \mathrm{kg})$, midazolam $(0.10-0.125 \mathrm{mg} / \mathrm{kg}$ for induction and 0.20 $\mathrm{mg} / \mathrm{kg}$ for maintenance), and pancuronium $(0.22 \mathrm{mg} / \mathrm{kg})$.

CPB with nonpulsatile perfusion flow $\left(2.2-2.4 \mathrm{~L} \cdot \mathrm{min}^{-1} \cdot \mathrm{m}^{-2}\right)$ was conducted by using membrane oxygenators with arterial line filtration. Mild hypothermia $\left(32^{\circ} \mathrm{C}\right)$ was maintained without topical cooling. Surgical techniques were the same in all cases. Aortic root and 2-stage single venous cannulas were used for CPB. A retrograde, self-inflating coronary sinus cardioplegia cannula (RC014; Research Medical Inc) with a pressure-monitoring port was guided into place. A 9-gauge cannula was placed in the aortic root for antegrade cardioplegia or for venting. Distal anastomoses were made in the order of right coronary artery-circumflex arteryleft anterior descending artery, and proximal anastomoses were constructed during crossclamping. Left internal thoracic artery to left anterior descending artery grafting was used in all patients.

Blood from the pump reservoir was mixed with crystalloid in a ratio of $4: 1$, yielding a cardioplegia solution with a $21 \%$ hematocrit value and $21 \mathrm{mmol} / \mathrm{L}$ potassium concentration in the initial dose and $9 \mathrm{mmol} / \mathrm{L}$ in subsequent doses. During antegrade delivery cardioplegia was administered at a pressure of $80 \mathrm{~mm} \mathrm{Hg}$ and 
during retrograde delivery at a pressure of 30 to $50 \mathrm{~mm} \mathrm{Hg}$, with a flow of at least $200 \mathrm{~mL} / \mathrm{min}$. The initial high-potassium cardioplegia was given 1.5 minutes antegrade and then 2.5 minutes retrograde at a temperature of $6^{\circ} \mathrm{C}$ to $9^{\circ} \mathrm{C}$. One minute of cardioplegia was given retrograde to right coronary artery and left circumflex artery area grafts after each distal anastomosis. Warm cardioplegia $\left(37^{\circ} \mathrm{C}\right)$ was given retrograde for 3 minutes before release of crossclamping.

\section{Measurements of AF}

Data from 24-hour ECG were collected 1 day before the operation and immediately after the operation until the second postoperative day (POD). Recordings of 24-hour ECG were performed with 2-channel tape recorders (Oxford Medilog MR 4500-3). The recordings were analyzed with Oxford Medilog Holter Management System Excel 2 software (release 8.5). Software-analyzed classifications of QRS complexes and events were checked on the computer screen and corrected manually. The analysis was blind to the investigators. The data were preserved and analyzed in the same period with the same standard.

$\mathrm{AF}$ was defined as an irregular narrow complex rhythm with absence of discrete $\mathrm{P}$ waves. AF was registered as positive if any AF event appeared for longer than 30 seconds. AF episodes of longer than 10 minutes were defined as sustained AF.

\section{Hemodynamics}

Hemodynamic data, including cardiac index and pulmonary capillary wedge pressure (PCWP), were collected at 4 time points: (1) baseline, before induction of anesthesia; (2) 1 hour after declamping; (3) 6 hours after declamping; and (4) on the first POD. All measurements on the basis of the thermodilution technique were made at end expirium in triplicate with ice-cold saline. The mean value of 3 consecutive measurements at each time point was registered.

\section{Postoperative Care}

Volume infusion was aimed to maintain the filling pressure at least at the preoperative level. Pharmacologic therapy with inotropes was used to keep the cardiac index at greater than $2.0 \mathrm{~L} \cdot \min ^{-1}$ $\mathrm{m}^{-2}$; this was not interrupted at the time points when hemodynamic data were taken. Dopexamine or adrenaline was used as the first-choice inotrope, and amrinone with noradrenaline was used if necessary. Electrolytes and acid-base balance were kept in the normal range. $\beta$-Blockers were used for all patients after weaning from the respirator. The cardiologist on duty undertook AF intervention, including medication and electrocardioversion, whenever needed. Electrocardioversion was used when amiodarone and flecainide failed. The intensive care unit (ICU) team and cardiologists were blinded in the management of postoperative care.

\section{Statistical Methods}

The unpaired Student $t$ test was used for continuous data (2-tail), and the $\chi^{2}$ or Fisher exact tests were used for categoric data when comparing variables between the groups. The Mann-Whitney $U$ test was used for skewed distributions. Repeated-measures analysis of variance was used to test repeated observation variables after the operation. Baseline values were used as a covariant when appropriate in the analysis. Variables such as IP and patient's age, sex, heart rate (HR), PCWP, preoperative and postoperative medication, cardiac function, $\mathrm{CPB}$, and crossclamping periods were entered for binary logistic regression backward likelihood ratio analysis to assess the independent predictors for AF. Continuous data were presented as means $\pm \mathrm{SD}$, and categoric data were presented as numbers of patients, with percentages in parentheses. The statistical analyses were performed with an SPSS/Win (version 10.0) statistical package program.

\section{Results \\ AF episodes}

Recordings of 24-hour ECG were maintained for $13.6 \pm 3.1$ and $14.1 \pm 2.4$ hours in the IP and control groups preoperatively $(P=.376), 21.2 \pm 1.1$ and $21.0 \pm 1.8$ hours on the first POD $(P=.405)$, and $23.3 \pm 2.5$ and $23.5 \pm 1.8$ hours on the second POD $(P=.687)$ for a total of $44.3 \pm$ 2.1 and $44.5 \pm 2.6$ hours postoperatively, respectively $(P=$ .856).

There were 4 patients, 2 in the IP group and 2 in the control group, with preoperative transient episodes of $\mathrm{AF}$ that lasted from 30 seconds to 4 minutes.

The overall incidences of postoperative AF and sustained AF were $34.1 \%$ and $27.1 \%$, respectively. The onset of AF was $21.4 \%$ on the first POD and $16.5 \%$ on the second POD. In patients with $\mathrm{AF}$, the mean period was $67.2 \pm 81.6$ minutes (1.0-240 minutes) on tape 2 and $202.9 \pm 213.9$ minutes (30-759 minutes) on tape 3. Most of the AF episodes appeared once. There were only 4 patients with 2 episodes of AF; the first episode usually passed within 5 minutes.

IP resulted in significantly less post-CABG AF. Sustained AF after the operation was also significantly suppressed in the IP group. The duration of AF episodes in the IP group was significantly decreased (Table 2).

\section{Outcome of Surgical Intervention}

IP resulted in better postoperative hemodynamic recovery. The period of mechanical ventilation was significantly shorter in the IP group than in the control group. The length of stay in the ICU was similar in both groups. More patients in the IP group were free of inotropes, and the period of inotropic medication use was also marginally shorter in the IP group than in the control group (Table 2). There was no perioperative myocardial infarction or early postoperative death. Intra-aortic balloon pumps were not required in any patients.

\section{AF Predictors and Postoperative Outcome}

Post-CABG AF was not related to the patient's age, sex, preoperative left ventricular ejection fraction, New York Heart Association classification, previous history of myocardial infarction, preoperative risk factors, diabetes, preoperative medication, severity of coronary vessel stenosis, aortic crossclamping period, number of vessels bypassed, 
TABLE 2. Postoperative outcome in IP and control group patients

\begin{tabular}{|c|c|c|c|}
\hline & $\begin{array}{c}\text { IP } \\
(n=42)\end{array}$ & $\begin{array}{c}\text { Control } \\
(n=43)\end{array}$ & $P$ value \\
\hline Postoperative AF & $9(21.4)$ & $20(46.5)$ & .015 \\
\hline Postoperative sustained AF & $5(11.9)$ & $18(41.9)$ & .002 \\
\hline$A F$ period $(\min )$ & $20.7 \pm 65.3$ & $74.0 \pm 165.7$ & .010 \\
\hline Respiratory treatment (h) & $12.2 \pm 3.5$ & $18.4 \pm 17.5$ & .028 \\
\hline ICU stay (h) & $35.1 \pm 25.0$ & $41.3 \pm 32.2$ & .323 \\
\hline Inotropes & $23(54.8)$ & $33(76.7)$ & .033 \\
\hline Inotropic period (h) & $10.1 \pm 10.9$ & $18.2 \pm 24.2$ & .057 \\
\hline Peak CK-MB & $22.0 \pm 10.3$ & $22.0 \pm 10.0$ & .984 \\
\hline $\begin{array}{l}\text { Postoperative use of } \\
\text { amiodarone }\end{array}$ & $3(7.1)$ & $5(11.6)$ & .479 \\
\hline $\begin{array}{l}\text { Postoperative use of } \\
\text { flecainide }\end{array}$ & $1(2.4)$ & $1(2.3)$ & .987 \\
\hline $\begin{array}{l}\text { Postoperative } \\
\text { electrocardioversion }\end{array}$ & $0(0)$ & $2(4.7)$ & .494 \\
\hline $\begin{array}{l}\text { CI (baseline, } \mathrm{L} \cdot \mathrm{min}^{-1} \text {. } \\
\mathrm{m}^{-2} \text { ) }\end{array}$ & $2.54 \pm 0.41$ & $2.60 \pm 0.55$ & .016 \\
\hline $\mathrm{Cl}\left(1 \mathrm{~h}, \mathrm{~L} \cdot \min ^{-1} \cdot \mathrm{m}^{-2}\right)$ & $2.69 \pm 0.56$ & $2.34 \pm 0.59$ & \\
\hline $\mathrm{Cl}\left(6 \mathrm{~h}, \mathrm{~L} \cdot \min ^{-1} \cdot \mathrm{m}^{-2}\right)$ & $3.22 \pm 1.01$ & $2.85 \pm 0.89$ & \\
\hline $\begin{array}{l}\mathrm{CI} \text { (first POD, L } \cdot \min ^{-1} \text {. } \\
\mathrm{m}^{-2} \text { ) }\end{array}$ & $3.23 \pm 0.78$ & $3.11 \pm 0.75$ & \\
\hline
\end{tabular}

Continuous data are presented as means $\pm \mathrm{SD}$, and categoric data are presented as numbers of patients (\%). $C K-M B$, Creatine kinase $\mathrm{MB} ; \mathrm{Cl}$, cardiac index.

and postoperative inotropic support. Neither recent unstable angina pectoris nor preoperative transient AF episodes contributed to postoperative AF. Patients with AF had longer ICU treatment periods and compromised postoperative hemodynamic outcomes (Table 3). Binary logistic regression analysis showed that without IP $(P=.013)$, higher preoperative HR $(P=.035)$ and higher PCWP on the first POD $(P=.047)$ were the independent predictors of AF.

\section{Discussion}

There is evidence that IP reduces the incidence of ischemiareperfusion-induced arrhythmias and results in more normal sinus rhythm in animal models and in human subjects. ${ }^{14-21}$ Whether IP reduces ischemia-reperfusioninduced AF has not been investigated. In the present study IP significantly reduced the incidence and severity of AF after CABG. This protective effect was not related to myocardial ischemia measured on the basis of creatine kinase MB levels. Thus the protective anti-AF effect was not related to the anti-ischemic protection other than as a direct consequence of IP. ${ }^{18}$ IP also resulted in less AF intervention and better postoperative outcome. The present results supported the previous findings that atrial arrhythmias can be reduced by IP. ${ }^{19-21}$

The present findings showed that AF is a common complication after CABG. AF was also associated with compromised postoperative hemodynamic outcome and longer
TABLE 3. Patients with and without postoperative AF

\begin{tabular}{|c|c|c|c|}
\hline & $\begin{array}{l}\text { With AF } \\
(n=29)\end{array}$ & $\begin{array}{l}\text { Without AF } \\
(\mathrm{n}=56)\end{array}$ & $P$ value \\
\hline Unstable & $16(55.2)$ & $25(44.6)$ & .357 \\
\hline Age (y) & $66.1 \pm 8.5$ & $64.8 \pm 9.9$ & .544 \\
\hline Age $\geq 65$ & $20(37.7)$ & $33(62.3)$ & .365 \\
\hline Age $<65$ & $9(28.1)$ & $23(71.9)$ & \\
\hline Sex (n of female) & $11(29.7)$ & $15(18.8)$ & .184 \\
\hline $\begin{array}{l}\text { Left ventricular ejection } \\
\text { fraction }\end{array}$ & $63.1 \pm 9.8$ & $60.9 \pm 10.9$ & .364 \\
\hline NYHA & $3.5 \pm 0.6$ & $3.4 \pm 0.7$ & .388 \\
\hline Preoperative transient $\mathrm{AF}$ & $1(3.4)$ & $3(5.4)$ & .694 \\
\hline Infarct history & $13(44.8)$ & $26(46.4)$ & .888 \\
\hline Diabetics & $4(14.8)$ & $15(27.8)$ & .194 \\
\hline Risk factor (Cleveland model) & $1.8 \pm 2.0$ & $1.5 \pm 1.5$ & .376 \\
\hline $\begin{array}{l}\text { Preoperative use of } \beta \text { - } \\
\text { blocker }\end{array}$ & $27(93.1)$ & $50(89.3)$ & .568 \\
\hline $\begin{array}{l}\text { Preoperative use of ACE } \\
\text { inhibitor }\end{array}$ & $7(24.1)$ & $11(19.6)$ & .631 \\
\hline $\begin{array}{l}\text { Preoperative use of } \mathrm{Ca}^{++} \\
\text {antagonist }\end{array}$ & $8(27.6)$ & $17(30.4)$ & .790 \\
\hline Left main stenosis $>50 \%$ & $11(37.9)$ & $17(30.4)$ & .481 \\
\hline Crossclamping time (min) & $79.6 \pm 25.3$ & $79.4 \pm 14.8$ & .967 \\
\hline Perfusion time (min) & $108.3 \pm 22.1$ & $111.9 \pm 19.0$ & .416 \\
\hline No. of bypasses & $3.7 \pm 0.9$ & $3.8 \pm 0.8$ & .642 \\
\hline Respiratory treatment (h) & $17.1 \pm 10.4$ & $14.3 \pm 13.7$ & .094 \\
\hline ICU (h) & $49.7 \pm 36.2$ & $32.3 \pm 22.5$ & .011 \\
\hline Peak CK-MB & $23.0 \pm 11.0$ & $19.9 \pm 7.7$ & .199 \\
\hline $\begin{array}{l}\text { Postoperative use of } \\
\text { amiodarone }\end{array}$ & $5(17.2)$ & $3(5.4)$ & .075 \\
\hline Inotropes & $22(73.0)$ & $34(50.0)$ & .163 \\
\hline Inotropic period (h) & $16.6 \pm 16.3$ & $12.8 \pm 20.1$ & .116 \\
\hline $\begin{array}{l}\text { Preoperative mean HR } \\
\text { (beats/min) }\end{array}$ & $62.1 \pm 9.0$ & $60.2 \pm 8.2$ & .195 \\
\hline $\begin{array}{l}\text { Mean HR first postoperative } \\
24 \mathrm{~h}\end{array}$ & $84.4 \pm 11.3$ & $83.8 \pm 17.9$ & \\
\hline $\begin{array}{l}\text { Mean HR second } \\
\text { postoperative } 24 \mathrm{~h}\end{array}$ & $79.0 \pm 12.1$ & $77.1 \pm 11.3$ & \\
\hline PCWP (baseline, mm Hg) & $12.7 \pm 4.8$ & $12.0 \pm 3.1$ & .360 \\
\hline $\begin{array}{l}\text { PCWP (postoperative } 1 \mathrm{~h} \text {, } \\
\mathrm{mm} \mathrm{Hg} \text { ) }\end{array}$ & $11.0 \pm 3.8$ & $11.6 \pm 2.5$ & \\
\hline $\begin{array}{l}\text { PCWP (postoperative } 6 \mathrm{~h} \text {, } \\
\mathrm{mm} \mathrm{Hg} \text { ) }\end{array}$ & $10.6 \pm 3.4$ & $11.8 \pm 3.5$ & \\
\hline PCWP (first POD, mm Hg) & $11.4 \pm 2.3$ & $10.7 \pm 2.7$ & \\
\hline $\mathrm{Cl}$ (baseline, $\mathrm{L} \cdot \mathrm{min}^{-1} \cdot \mathrm{m}^{-2}$ ) & $2.59 \pm 0.60$ & $2.57 \pm 0.44$ & .019 \\
\hline $\begin{array}{l}\mathrm{Cl} \text { (postoperative } 1 \mathrm{~h}, \mathrm{~L} \text {. } \\
\min ^{-1} \cdot \mathrm{m}^{-2} \text { ) }\end{array}$ & $2.45 \pm 0.68$ & $2.55 \pm 0.53$ & \\
\hline $\begin{array}{l}\mathrm{Cl} \text { (postoperative } 6 \mathrm{~h}, \mathrm{~L} \text {. } \\
\min ^{-1} \cdot \mathrm{m}^{-2} \text { ) }\end{array}$ & $2.78 \pm 0.92$ & $3.16 \pm 0.96$ & \\
\hline $\mathrm{Cl}$ (first POD, $\mathrm{L} \cdot \mathrm{min}^{-1} \cdot \mathrm{m}^{-2}$ ) & $2.91 \pm 0.76$ & $3.25 \pm 0.74$ & \\
\hline
\end{tabular}

Continuous data are presented as means $\pm S D$, and categoric data are presented as numbers of patients (\%). Heart rate was measured with the Holter recording apparatus. NYHA, New York Heart Association; $A C E$, angiotensin-converting enzyme; $C K-M B$, creatine kinase $\mathrm{MB}$; $\mathrm{Cl}$, cardiac index.

ICU treatment time. Patients with AF tended to be related to greater need for inotropic support, postoperative amiodarone medication, and longer mechanical ventilation periods. 
Pharmacologic prophylactics with the blockers sotalol and amiodarone are well supported by randomized clinical trials. ${ }^{2,3,8,22}$ However, there was still a high incidence of AF in the present study, even with the use of $\beta$-blockers. The efficacy and higher costs, more severe side effects, and more complicated implementation limit the use of sotalol and amiodarone. The usefulness of nonpharmacologic strategies, such as continuous overdrive atrial pacing through temporary epicardial electrodes, is currently under investigation. $^{2,3,8,22}$ A more readily applicable strategy for the prevention of post-CABG AF would therefore be highly desirable. The present findings suggest that IP can be used as an effective prophylactic method for postoperative AF.

The mechanism involved in the IP effect of suppressing postoperative AF is not known. Studies show that IP reduces the inhomogeneity and modifies the ion channels, preventing the conduction delays necessary for transmural re-entry and resulting in fewer arrhythmias. ${ }^{15,19-21}$ Other authors have suggested that the antiarrhythmic protection afforded by IP might be mediated by preservation of autonomous function. ${ }^{14}$ The autonomic nervous system has previously been implicated in both the ignition and perpetuation of $\mathrm{AF}$ after $\mathrm{CABG} .^{2,7}$ This implies that the IP effect in suppressing post-CABG AF might be mediated by preservation of autonomous function.

The IP effects in suppressing post-CABG AF might be a subsequent result of the other protective effects. Better hemodynamic recovery, less inotropic support, and shorter respiratory ventilation might be associated with less AF. ${ }^{1,2,21}$ Inotropes might cause the heart to increase its work output beyond its energy supply. This energetic supply and demand inequality might impair membrane ionic pumps and allow the membrane potential to drift upward toward the threshold, thereby increasing automaticity. ${ }^{2,21}$ Logistic regression analysis here showed that IP was an independent predictor of AF. Thus the protective effect against postCABG AF seems to be a direct consequence of IP.

The cause of postoperative AF is not well known. ${ }^{8} \mathrm{~A}$ number of factors have been claimed to be associated with post-CABG AF. ${ }^{1-9,21,23-25}$ However, large and well-conducted observational studies have yielded conflicting results on the independent predictive value of these factors. ${ }^{1,4,5,8,9,23-25}$ In our study we found higher preoperative HR and postoperative PCWP values in relation to the occurrence of AF. The results were in concordance with those of one previous report. ${ }^{9}$ Older age has consistently predicted a higher incidence of postoperative $\mathrm{AF} .{ }^{8}$ Here we did not find age to be correlated with AF. Concerning the relatively small study cohort, only a tendency of relatively lower postoperative AF occurrence in younger patients was found. This phenomenon is similar to our previous finding. ${ }^{23} \mathrm{Be}-$ cause we used $\beta$-blockers in all patients postoperatively, their effect could not be shown here. Higher preoperative
HR predisposed to postoperative AF indicated the importance of $\beta$-blocker prophylaxis. It has been reported that myocardial ischemia might predispose to postoperative $\mathrm{AF},{ }^{23,24}$ and unstable angina before surgical intervention might thus be related to more post-CABG AF. The present study showed that unstable angina was not related to the incidence of AF, which is similar to the results of 2 previous studies. ${ }^{5,8}$ Our study did not support the previous finding that paroxysmal AF associates with postoperative AF. ${ }^{9}$ Differences in patient selection might account for this difference.

One limitation is the small population investigated. Small samples can not be used to derive a satisfactory statistical analysis of different perioperative variables, possibly influencing atrial arrhythmogenesis. ${ }^{9}$ On the other hand, this did not influence the finding that IP significantly suppresses postoperative AF. Another limitation is the recording period lasting only 45 hours postoperatively, so as not to cause inconvenience and discomfort to the patients. The incidence of AF might be higher and the sensitivity and specificity for analysis of data would be more appropriate if the recording time was longer.

\section{References}

1. Maisel WH, Rawn JD, Stevenson WG. Atrial fibrillation after cardiac surgery. Ann Intern Med. 2001;135:1061-73.

2. Olshansky B. Management of atrial fibrillation after coronary artery bypass graft. Am J Cardiol. 1996;78(8A):27-34.

3. Pinski SL, Lee JK. Prevention of postoperative atrial fibrillation: lukewarm progress. Crit Care Med. 2000;28:574-5.

4. Creswell LL, Damiano RJ Jr. Postoperative atrial fibrillation: an old problem crying for new solutions. J Thorac Cardiovasc Surg. 2001; 121:638-41.

5. Cohn WE, Sirois CA, Johnson RG. Atrial fibrillation after minimally invasive coronary artery bypass grafting: a retrospective, matched study. J Thorac Cardiovasc Surg. 1999;117:298-301.

6. Willems S, Weiss C, Meinertz T. Tachyarrhythmias following coronary artery bypass graft surgery: epidemiology, mechanisms, and current therapeutic strategies. Thorac Cardiovasc Surg. 1997;45:232-7.

7. Kalman JM, Munawar M, Howes LG, et al. Atrial fibrillation after coronary artery bypass grafting is associated with sympathetic activation. Ann Thorac Surg. 1995;60:1709-15.

8. Mueller XM, Tevaearai HT, Ruchat P, et al. Did the introduction of a minimally invasive technique change the incidence of atrial fibrillation after single internal thoracic artery-left anterior descending artery grafting? J Thorac Cardiovasc Surg. 2001;121:683-8.

9. Ducceschi V, D'Andrea A, Liccardo B, et al. Perioperative clinical predictors of atrial fibrillation occurrence following coronary artery surgery. Eur J Cardiothorac Surg. 1999;16:435-9.

10. Murry CE, Jennings RB, Reimer KA. Preconditioning with ischemia: a delay of lethal cell injury in ischemic myocardium. Circulation. 1986;74:1124-36.

11. Tarkka MR, Wu ZK. Ischemic preconditioning in cardiopulmonary bypass surgery. Scand Cardiovasc J. 2000;34:231-2.

12. Wu ZK, Tarkka MR, Pehkonen E, et al. Beneficial effects of ischemic preconditioning on right ventricular function after coronary artery bypass grafting. Ann Thorac Surg. 2000;70:1551-7.

13. Wu ZK, Pehkonen E, Laurikka J, et al. The protective effects of preconditioning subside in the aging CABG patients. $J$ Thorac Cardiovasc Surg. 2001;122:972-8.

14. Miyazaki T, Zipes DP. Protection against autonomic denervation fol- 
lowing acute myocardial infarction by preconditioning ischemia. Circ Res. 1989;64:437-48.

15. Parratt J, Vegh A. Pronounced antiarrhythmic effects of ischemic preconditioning. Cardiosciences. 1994;5:9-18.

16. Zhu J, Ferrier GR. Ischemic preconditioning: antiarrhythmic effects and electrophysiological mechanisms in isolated ventricle. Am J Physiol. 1998;274:H66-75.

17. Okishige K, Yamashita K, Yoshinaga H, et al. Electrophysiologic effects of ischemic preconditioning on QT dispersion during coronary angioplasty. J Am Coll Cardiol. 1996;28:70-3.

18. Pasceri V, Lanza GA, Patti G, et al. Preconditioning by transient myocardial ischemia confers protection against ischemia-induced ventricular arrhythmias in variant angina. Circulation. 1996;94:1850-6.

19. Airaksinen KE, Huikuri HV. Antiarrhythmic effect of repeated coronary occlusion during balloon angioplasty. J Am Coll Cardiol. 1997; 29:1035-8.

20. Pomerantz BJ, Joo K, Shames BD, et al. Adenosine preconditioning reduces both pre and postischemic arrhythmias in human myocardium. J Surg Res. 2000;90:191-6.

21. Cain BS, Meldrum DR, Meng X, et al. Therapeutic antiarrhythmic and functional protection in human atria. J Surg Res. 1998;76:143-8.

22. Crystal E, Connolly SJ, Sleik K, et al. Interventions on prevention of postoperative atrial fibrillation in patients undergoing heart surgery: a meta-analysis. Circulation. 2002;106:75-80.

23. Pehkonen EJ, Makynen PJ, Kataja MJ, et al. Atrial fibrillation after blood and crystalloid cardioplegia in CABG patients. Thorac Cardiovasc Surg. 1995;43:200-3.

24. Pehkonen E, Honkonen E, Makynen P, et al. Stenosis of the right coronary artery and retrograde cardioplegia predispose patients to atrial fibrillation after coronary artery bypass grafting. Thorac Cardiovasc Surg. 1998;46:115-20.

25. Pires LA, Wagshal AB, Lancey R, et al. Arrhythmias and conduction disturbances after coronary artery bypass graft surgery: epidemiology, management, and prognosis. Am Heart J. 1995;129:799-808.

\section{Authoritative}

The Journal of Thoracic and Cardiovascular Surgery is the most frequently cited thoracic/cardiovascular surgery journal in the Science Citation Index. An article in JTCVS is cited on average almost twice as often as those in the closest cardiothoracic journal. 